\title{
QUEEN'S
UNIVERSITY
BELFAST
}

\section{The challenge of patients' unmet palliative care needs in the final stages of chronic illness.}

Fitzsimons, D., Mullan, D., Wilson, J. S., Conway, B., Corcoran, B., Dempster, M., Gamble, J., Stewart, C., Rafferty, S., McMahon, M., McMahon, J., Mulholland, P., Stockdale, P., Chew, E., Hanna, L., Brown, J., Ferguson, G., \& Fogarty, D. (2007). The challenge of patients' unmet palliative care needs in the final stages of chronic illness. Palliative Medicine, 21(4), 313-322. https://doi.org/10.1177/0269216307077711

Published in:

Palliative Medicine

Document Version:

Early version, also known as pre-print

Queen's University Belfast - Research Portal:

Link to publication record in Queen's University Belfast Research Portal

Publisher rights

(2007 The Authors

\section{General rights}

Copyright for the publications made accessible via the Queen's University Belfast Research Portal is retained by the author(s) and / or other copyright owners and it is a condition of accessing these publications that users recognise and abide by the legal requirements associated with these rights.

Take down policy

The Research Portal is Queen's institutional repository that provides access to Queen's research output. Every effort has been made to ensure that content in the Research Portal does not infringe any person's rights, or applicable UK laws. If you discover content in the Research Portal that you believe breaches copyright or violates any law, please contact openaccess@qub.ac.uk. 


\section{TOO LITTLE, TOO LATE: MEETING THE PALLIATIVE CARE NEEDS OF PATIENTS WITH CHRONIC ILLNESS}




\section{Authors:}

Fitzsimons D, RGN, BSc, PhD.

Director of Nursing Research \& Development, Belfast City Hospital \& Reader, Institute of Nursing Research, University of Ulster, Northern Ireland.

Mullan D, RGN, BSc.

Nurse Researcher, Belfast City Hospital, Northern Ireland.

Wilson J S, RGN, BSc, PhD.

Nurse Researcher, Belfast City Hospital, Northern Ireland.

Conway B, RGN

Lead Nurse Palliative Care, Belfast City Hospital, Northern Ireland.

Corcoran B

Consultant in Palliative Medicine, Belfast City Hospital, Northern Ireland.

Dempster M, BSc, MSc, PhD, CPsychol, CStat

Research Co-Ordinator, Psychology Department, Queen's University of Belfast, Northern Ireland. Gamble J, RGN, BSc.

Sister, Out Patients Chest Clinic, Regional Respiratory Centre, Belfast City Hospital, Northern Ireland.

Stewart C, RGN, BSc.

Specialist Nurse, Regional Respiratory Centre, Belfast City Hospital, Northern Ireland.

Rafferty S RGN, BSc, MSc.

Specialist Nurse, Regional Respiratory Centre, Belfast City Hospital, Northern Ireland.

McMahon M RGN

Specialist Nurse, Heart Failure, South \& East Belfast Trust, Northern Ireland

McMahon J

Consultant Respiratory Physician, Regional Respiratory Centre, Belfast City Hospital, Northern

Ireland.

Mulholland P, RGN

Heart Failure Nurse Specialist, Cardiology Department, Belfast City Hospital, Northern Ireland. Stockdale P, RGN, BSc, MSc

Heart Failure Nurse Specialist, Specialist Medicine Directorate, Belfast City Hospital, Northern Ireland.

Chew $\mathrm{E}$

Consultant Cardiologist, Cardiology Department, Belfast City Hospital, Northern Ireland.

Hanna L RGN

Renal Education Nurse Specialist, Regional Nephrology Unit, Belfast City Hospital, Northern Ireland.

Joan

Renal Education Nurse Specialist, Regional Nephrology Unit, Belfast City Hospital, Northern Ireland.

Gail Ferguson

Renal Education Nurse Specialist, Regional Nephrology Unit, Belfast City Hospital, Northern Ireland.

Fogarty D

Consultant Nephrologist, Regional Nephrology Unit, Belfast City Hospital, \& Senior Lecturer, Queen's University, Belfast, Northern Ireland.

\section{ADDRESS FOR CORRESPONDENCE:}

Dr Donna Fitzsimons

Director of Nursing Research \& Development

Belfast City Hospital \&

Reader, University of Ulster,

Belfast

BT9 7AB

Donna.fitzsimons@bch.n-i.nhs.uk

Tel: 02890329241 Ext 2984 


\begin{abstract}
Background: This study aimed to use a mixed methodology and case study approach to explore the palliative care needs of patients with a non-cancer diagnosis from the perspectives of the patient, their significant other and the clinical team responsible for their care. Patients $(n=18)$ had a diagnosis of either end-stage heart failure, renal failure or respiratory disease.

Methods: The SF36 and Hospital and Anxiety and Depression Questionnaire were completed by all patients. Unstructured interviews were $(n=35)$ were conducted separately with each patient and then their significant other. These were followed by a focus group discussion $(n=18)$ with the multiprofessional clinical team. Quantitative data were analysed using SPSS and simple descriptive statistics. All qualitative data were taped, transcribed and analysed using Colaizzi's approach to qualitative analysis.
\end{abstract}

Findings: Deteriorating health status was the central theme derived from this analysis. It led to decreased independence, social isolation and family burden. These problems were mitigated by the personal resources at the individual's disposal and the availability of support from hospital and community services. All participants in this study expressed concerns regarding the patients' future and some patients described feelings of depression or acceptance of the inevitability of imminent death.

Conclusion: Patients dying from chronic illness in this study had many concerns and unmet clinical needs. Care teams were frustrated by the lack of resources available to them and admitted they were ill-equipped to provide for the individual's holistic needs. Some clinicians described difficulty in talking openly with the patient and family regarding the palliative nature of their treatment. An earlier and more effective implementation of the palliative care approach is necessary if the needs of patients in the final stages of chronic illness are to be adequately addressed.

\title{
KEY WORDS:
}

Heart failure, respiratory failure, renal failure, palliative care, chronic illness, case study. 


\section{Introduction}

Despite their typically insidious onset and potentially preventable nature, chronic illnesses are the major causes of mortality and morbidity in the developed world to-day. Mortality data for the United Kingdom show that 608000 people died in 2000; 25\% of these were from cancer, $17 \%$ from respiratory disease and $26 \%$ from heart disease 1. Chronic illnesses represent the modern epidemic and there are many disease trajectories where therapeutic options have been exhausted and patients pass from a chronic illness phase, to a terminal stage. There is evidence to suggest that these patients may require palliative and supportive care services, even though they suffer from a non-malignant disease $\mathrm{e}^{2-4}$. However, with some notable exceptions such as motor neurone disease and HIV, palliative care provision in non-cancer illnesses is not well developed in Europe, although if we take the lead from USA this may improve ${ }^{5}$. While research on the palliative care needs of chronic illness populations is scant, the emerging evidence suggests that they may share many of the problems experienced by patients with a cancer diagnosis towards the end of their life ${ }^{6-8}$.

Heart failure and end stage respiratory disease are among the most common causes of death in hospitalized patients ${ }^{5,9}$. Yet the palliative care needs of these patients have, until recently, been largely ignored ${ }^{10}$. Addington-Hall and McCarthy's ${ }^{11}$, seminal study of 675 patients who had died from heart disease, confirmed the distressing and poorly managed symptoms that often characterized their declining health. The palliative care needs of heart failure patients has since gained prominence ${ }^{12,13}$. Similarly, comparisons between terminally ill lung cancer patients and patients with COPD, reveal that those with COPD have a poorer quality of life and more anxiety and depression ${ }^{14,5}$. End-stage renal disease is also characterised by reduced quality of life ${ }^{15}$, and a recent report suggests the merit in adopting palliative care approaches for these patients in the final stages of their illness ${ }^{16,17}$.

While it is useful to acknowledge the similarities between the palliative care needs of patients with cancer and chronic illnesses, particular differences are also evident ${ }^{18}$. Individuals with chronic illness often have a more prolonged illness trajectory than cancer patients and for that reason may have different palliative care needs ${ }^{6}$. Chronic illness typically robs individuals of physical and psychological well being, employment, hobbies, friends and self esteem from an earlier age than those with cancer. Thus, after 
decades of progressive deterioration in their health and functional ability, individuals with chronic illness often reach the terminal phase of their life without many of the physical and social resources other dying patients may avail of ${ }^{19}$. In addition, it may be difficult to determine when the treatment in chronic illnesses should move its focus from therapeutic to palliative intent ${ }^{7}$. This is a problem because the lack of diagnostic certainty, which is more predictable in cancer, can be the lever by which professional teams caring for the chronically ill can mobilise the additional health care resources required to meet patients' palliative and supportive care needs.

This study was initiated by specialist multiprofessional teams who had expressed concerns regarding the level of palliative care service provision that was available to those with chronic illness in the final chapter of their lives. The study aimed to explore the palliative care needs of non-cancer patients, and to describe the views of their significant other and their clinical care team on this subject.

\section{Method}

Given the stated aim and objectives of this study a case study approach was selected as the most appropriate method of data collection ${ }^{20}$, as it is a particularly useful way to collect in-depth, complex and contextual data from multiple perspectives ${ }^{21-22}$. Data were collected from three main sources - the patient, their main carer and the clinical team. Semi-structured, qualitative interviews using open questions were selected as the main tool of data collection, to enable the participants to describe their experience in detail, while retaining focus on the phenomena of interest. In addition, the Short Form 36 $\left(\right.$ SF36) ${ }^{23}$ and Hospital Anxiety and Depression Questionnaire (HADS) ${ }^{24}$ evaluated patients' functional status and emotional state.

The SF36 is a 36-item instrument divided into eight scales - physical functioning, social functioning, general health, role limitations due to emotional problems, role limitations due to physical problems, vitality, bodily pain, and mental health. The SF-36 has been validated extensively on general populations and different diseases, demonstrating high reliability and good construct validity (Ware et al. 1997, McHorney et al. 1994).

The HADS is a 14 item scale which is divided into two dimensions - anxiety (7 items) and depression (7 items). Respondents choose one from four responses to each item. 
Their responses are then summed within dimensions and a total score for each dimension is obtained. Scores for the anxiety dimension and the depression dimension are interpreted as follows: 0-7: normal, 8-10: mild, 11-14: moderate, 15-21: severe. Evidence exists to support the reliability and validity of the HADS (Bjelland et al., 2002).

\section{Setting \& Sample}

The study was set in an 800 bed regional hospital, housing several clinical specialties including renal, respiratory, cardiac and palliative care. The project was approved by the local research Ethics Committee. The physical and emotional needs of research participants were regarded as paramount throughout, and process consent was used so that participants were regularly reminded that they could refuse to answer any specific question or terminate interviews at any time. A purposive sample of 18 patients was selected through detailed discussion between researcher and specialist clinicians. Patients had to be over 18 years old, be fully aware of the palliative intent of their treatment, deemed physically and mentally capable of participation in this project, and willing to provide informed consent. Exclusion criteria included those living in nursing homes and those on a transplant list or with an existing cancer diagnosis. Semistructured interviews were conducted with patients in their own home. Each had a diagnosis of either, end stage heart failure $(n=6)$, renal failure $(n=6)$, or respiratory disease $(n=6)$, as defined by disease-specific clinical parameters. See Table 1. A separate interview was conducted with their specified significant other $(n=17)$ and a focus group $(n=18)$ was convened to discuss each case with the multidisciplinary clinical team responsible for providing care to the individual patient.

\section{Data Collection}

A semi-structured interview schedule, with open questions was used to guide initial interviews. An inductive technique was employed, so that participants' views and concerns, rather than those of the researcher, were allowed to guide the interview and focus group content ${ }^{20}$. Thus, after the first one or two interviews, these subsequently focused on the topics and issues raised by participants themselves. In each case study the patient was interviewed first, then the carer, and finally the focus group with the clinical team was conducted. The aim of using this sequence of data collection was to keep the study focused on issues that were important to patients and their carers. The self-report scales were completed after patient interviews, or at a later stage if the patient 
was tired. Data collection typically lasted about an hour (range 45 - 100 mins). All interviews with patients and carers took place separately in the participant's home and focus groups with clinical team were undertaken in a quiet room in the hospital setting. One researcher (DM) undertook all data collection and analysis, with the support of an experienced researcher (DF) and palliative care nurse specialist (BC).

\section{Data Analysis}

All interviews and focus groups were taped and transcribed verbatim. The researcher listened to the tapes following transcription to insert any missing or contextual data. Analysis of the data was conducted using the procedural steps outlined by Colaizzi ${ }^{25}$. Throughout the analysis process the researcher continuously read and re-read the transcripts, sorting the data into categories and grouping these under themes. The relationship between the themes was explored, and transcripts re-read to confirm or refine the relationships between themes. The intention was to arrive at an exhaustive description of the phenomena of interest.

Quantitative data (obtained from the SF36 and the HADS) were summarised using mean scores for each group. Further statistical analyses were considered inappropriate, given the sample sizes in each group. The quantitative data were, therefore, effectively used to describe the characteristics of the group.

\section{Findings}

Quantitative findings confirmed that patients were from a broad age range and that they had high levels of morbidity on the SF36 and Hospital Anxiety and Depression Questionnaire, and that most of these patients were in the last months of their lives (Table 2). The quantitative data are consistent with the qualitative findings. Through the detailed analysis process qualitative data were organized into eight interdependent themes as illustrated in Figure 1. This model is presented to summarise the data, describe how the themes were inter-related and convey an understanding of participants' experiences. Each theme will be presented individually, with quotations used to illustrate content. 
(Figure 1.)

\section{Deteriorating health status}

Deteriorating health status was the strong central theme, which had a profound impact on patients' overall quality of life. The other themes defined in this analysis, appeared to stem from this deterioration. It was evident that patients, carers and clinical teams were all very aware of patients' failing health.

Pt 7 (Heart Failure) I have no quality of life, I used to be very active and enjoyed going out. Now I can't walk very far and have to depend on my daughter to take me out in the car.

Pt 7 (Carer) His health has deteriorated over these past 2 years. He cannot walk because he gets short of breath and tired. He sits around a lot and is bored.

Pt 7 (Clinical Team) I have seen a stepwise in deterioration in that each time he gets better, he is not back to as well as he was before. That gets him down.

These quotations illustrate that declining health is a significant problem in this sample leading to a range of physical, social and emotional consequences for both patients and carers, that is well recognized by the clinical team.

\section{Decreased independence}


Decreased independence was associated with deterioration in health and was common among all the disease groups. Feelings of frustration with progressive loss of independence were a common feature expressed by most of the participants. These arose out of the ability to perform what, prior to the onset of their illness, were considered common tasks.

Patient 6 (Respiratory) Pt 6 (Carer) Recently I have been feeling lousy, absolutely lousy. The problem is if I exert myself in anyway the shortness of breath comes. As you can see I have oxygen all the time. My health is worse than it is has ever been...Frustration is the worst thing.

Pt 6 (Clinical Team)There has been a very big change in him over this past year. His breathing has got a lot worse. He was a very independent man. He gets very frustrated because he can't do things.

Interview data confirmed that losing independence was difficult for both patients and their carers to come to terms with. There was evidence that tempers tended to become frayed, as patients perceived they were being 'mothered' by over-protective family members and became frustrated and angry as a result

Pt 2 (Heart Failure) To tell you the truth; I would be a bit nasty to my wife. Everything gets me agitated. She's too caring and tries to mother me too much. It seems to get too much for me.

Pt 2 (Carer) He can really do nothing. He has got a little more snappy. He is not as pleasant as he used to be, probably because of frustration.

These extracts confirm the difficulty for patients in coming to terms with their reduced functional ability, and the subsequent problems this may cause for those caring for them.

\section{Social Isolation}

Social isolation caused by mobility restrictions was described by most of the participants in the three groups. It was more evident in the respiratory cohort, due to the need to use long- term oxygen therapy, which further restricted some patients to staying in certain 
rooms in their homes. Some patients described feelings of embarrassment in relation to control over their symptoms, which was another disincentive for going out.

Pt 15 (Respiratory) I live on my own. This is a sheltered dwelling; there are a lot of old people here. I'm only 57, so they're a lot older than me. I have been trying to get out of here for a few years now. l'd like a little bungalow, because there are so many old people. You see I wear oxygen 24 hours a day...If I go out in the car; I have to have the oxygen. I have a mobile one, which I carry with me when I go to the shops. I can't do it everyday. It depends how I feel.

Pt 15 (Clinical team) $\mathrm{He}$ is socially isolated, and even the provision of ambulatory oxygen does little to relieve this, because the stigma of being seen with a cylinder is a deterrent in itself. However his determination at present means that he will make an effort to get out and about.

It was evident that many carers had also become socially isolated as a result of their dependants' poor health status and reliance on them to assist with daily activities.

PT 14 (Respiratory) (Carer) We have got in a rut. We haven't been out in 14 years now. My brother got married two weeks ago and we didn't even go to the wedding. I don't bother with my family. They don't understand. They tell me I need to get out on my own.

Thus it is apparent that while the terminally ill individual was often troubled by their social isolation their carers too felt isolated as a result of their loved one's dependence on them.

\section{Family Burden}

Decreased independence and social isolation combined to impose a considerable burden of care on the family.

Pt 14 (Respiratory) My wife does every thing. If I have a shower I need her to do my back and legs. I try and do where I can reach. I can near enough dress myself; she would put on my socks and shoes. If I bend over I get out of breath. I'm not old, only 48years and it is hard at times because I can't do things myself. 
It was notable that most carers conveyed their willingness to look after dependants despite the difficulties they encountered.

Pt 8 (Heart Failure) (Carer) He can really do nothing. I'm 79 now and not as active as I was. I find it a bit difficult now, he is getting a bit harder for me to manage, but l'm used to the good times and the bad... If he keeps at this level I don't mind looking after him. He would do it for me, so I do it for him.

Consequently, many patients expressed feelings of guilt because of their reliance on family members to look after them.

Pt 17 (Respiratory) As you go along, you can feel yourself deteriorating. My daughter does all for me. She is only 21. Well, it is no life for her either, is it?

The burden placed on carers is evident in these excerpts, it would seem that there was little in the way of support or respite services offered to them, which raises questions regarding the carers' quality of life, although that was not evaluated in this study.

\section{Resources Available}

Participants in this study relied heavily on the range of personal resources available to them. Most of the participants identified family and friends as their main source of support in providing physical and emotional care.

PT 18 (3) (Respiratory) My wife is my main support she does everything for me.

Specialist nurses from the various outpatient clinics were cited as the main source of professional support.

PT 13 (Respiratory) (Carer) The nurse from the chest clinic is the only one I feel meets her needs. I don't know the rest, but she is the only one that comes out here to try and help her. Her own GP only comes when I phone. He only comes in here if I ring up and say she isn't well. He wouldn't just call in to see how she is doing or anything. I don't know if it is expected of him, but he doesn't do it.

In a few cases patients cited a wider circle of multidisciplinary involvement that they found beneficial: 
PT 2 (Renal) The doctors, nurses and social workers have been very helpful. The priest coming out makes me feel good. I am able to talk to him about a lot of things.

However, an extensive support network was described only in a few cases. Many participants in this study conveyed a need for greater support and additional resources to meet their needs.

Pt 12 (Heart Failure) I think there should be more help given to people in my situation. I know that cancer is the big thing and there are other top priority diseases, but I'm sure there a lot of people like me. Trying to get an even ground would be helpful, but you just seem to be forgotten about. I think you are slotted away and forgotten about.

These extracts confirm that participants' personal resources such as family, friends and professional help were very important to them, but that they felt their need for such resources exceeded their availability. Most patients and carers expressed a desire for greater support in the community. The clinical teams confirmed this also:

Clinical team (Heart Failure) There is a lack of support in the community. There isn't anything specifically for these chronically ill patients who don't have cancer. There aren't enough palliative care people to look after cancer patients in this area, never mind seeing people who haven't cancer. So you are see patients with heart failure are not getting support. Psychosocial and emotional support is a big issue for these patients so if there was somebody, a nurse, or somebody educated in palliative care issues to call with these patients, that would be a big help.

It was evident that hospital-based clinical teams were ill-equipped to meet the needs of this population. Clinicians in the three groups expressed their concerns about the level of support they could offer to patients from an outpatient setting.

Clinical team (Renal) You can't assess every single patient, you don't have the time to sit for half an hour and ask them how they are getting on at home. You can see a lot of the time they are deteriorating, but what are you meant to do? You might know that there are difficulties but how are you meant to actually go forward? It is hard to know. 
Clinical team (Heart Failure) You can see that his quality of life is poor, as well as his wife's, and it is an effort for them coming to the clinic. What concerns me is, what will happen when they are not fit enough to come to the clinic? I think some sort of respite or domiciliary visits would certainly improve their quality if life, as well as giving them some support. There is only so much we can do from an outpatient clinic.

It is evident from this data that clinical teams also expressed frustration at the level of service they were able to offer and were contemplating potential solutions to this issue.

\section{Access to Community Services}

Patients in each of the three diagnostic groups described difficulties in accessing services in the community.

PT 3 (Renal, Carer) He doesn't see the G.P very much. I think maybe the GP should have been out more to see him, but the GP's are busy.

There was also disparities in the level of care available to patients when they transferred from hospital to community:

PT3 (Renal, Clinical team) If a client is having difficulties and they are an in-patient we would ask physio and OT to see them. But this only happens if they are an in-patient. If they are an outpatient for dialysis, referral must be from their GP. We would advise the patient or the carer to contact the GP, or I would ask the GP for an urgent referral, but there is a bit of a gap here.... There must be a better means of referral and I will follow that up.

It was also evident that facilities were limited in the community, which caused feelings of frustration and imposed added burden on carers.

PT 18 (Respiratory) The thing about it is at the moment I have nothing. I can't even go up the stairs. I am sleeping down here. I have applied for a stair lift and a wheelchair because if they get me into the car I need a wheelchair.... That was three months ago and I have heard nothing yet. 
Accessing appliances and financial benefits were identified as a major difficulty by patients. It was also noted that accessibility to such services depended on the locality where patients lived and services were poorly co-ordinated. Participants also described a financial burden, which was a source of distress to some.

PT 9 (Heart Failure) We don't get any allowances apart from our pension. As a matter of fact, we are contemplating moving into some sort of sheltered accommodation. The up keep of the house is becoming more difficult, like painting or anything at all; it has to be paid for. To keep this place the way we want to is too expensive. We applied for attendance allowance and were turned down.

PT 9 (Carer) We applied for attendance allowance and got turned down, Well, I'm sure we have spent $£ 500$ on taxis. I'm not saying we should get the high rate, but even $£ 20$ a week would help.

The clinical teams were very aware of these issues, and recognized that patients needed information and support to assist them to apply for additional community resources.

PT 9 (Clinical team) Often asking for financial and practical help is difficult for them. Knowing what is available and how to access it is often the first hurdle.

These extracts confirm that participants in this study perceived the availability of community services, specialist appliances and financial assistance as poor for this population, although it is also important to note that clinical teams were focused on improving some aspects of this situation.

\section{Acceptance}

Many participants conveyed their feelings of acceptance with the stage they were at in their illness trajectory and expressed insight to their poor prognosis.

PT 13 (Respiratory) I know I am not going to get any better. My Consultant is a very fair man, he always tells me the truth. He doesn't beat about the bush. He told me I would really need a lung transplant. He told me the weed (tobacco) was going to win if I didn't get off it. 
PT 2 (Renal) I have all my funeral arrangements made. My doctor says he can't do anything for me. I am living on borrowed time. It's a fact. I just take things a day at a time now. I don't make any plans now.

Usually the clinical teams were satisfied that they had done all they could to make patients and their families aware of their terminal prognosis.

PT 2 (Clinical team) I think she is an intelligent woman. She has talked through her diagnosis and what the treatment options are and what can be expected from her individual treatments.

Carers also seemed well informed regarding this eventuality:

PT 11 (Heart Failure, Carer) I understand how serious it is from the last time he was ill. They told me that he wouldn't go on for much longer. I was devastated, but it needed to be said, and I wanted to know.

Some clinicians however expressed their difficulties with communicating poor prognosis to patients.

Clinical Team (Respiratory) So how did I address that? I didn't tell him. I don't think I have ever spelt out to him on a one to one. It has been very difficult to communicate that with him, to tell him that I think he has got a very low chance of surviving. I have told him in general terms that his condition is very serious. I would be honest and say that I often find it difficult to say to patients what the percentage chance of survival is. It wouldn't be my style.

Clinical team (Renal) We don't want to take away their hope. We are not ready to talk about terminal care.

These very honest extracts confirm that some clinicians who have developed a relationship with their chronically ill patient at a much earlier stage of the illness trajectory, can find it challenging to tell the patient when they have exhausted the therapeutic options available. However, it is notable that patients at the center of both 
these case studies were aware of their terminal prognosis, despite the clinical team's reticence to discuss it more openly.

\section{Depression}

Several participants described their feelings of depression, which was mostly attributed to their decline in health and inability to undertake daily activities.

Pt 11 (Heart Failure) I don't feel like going out. I have been feeling depressed... I just didn't want to get out of bed. I felt the same way as I did when I when I went into hospital. I feel absolutely rotten. I couldn't care less about anything.

PT 4 (Renal, Carer) He has been a bit down. He has been depressed and that. About eight months ago he was really depressed because he couldn't do anything for himself and he said that he couldn't even post a letter for himself.

Often it was the carers who felt the brunt of the patients' low moods;

Pt 11 (Heart Failure) (Carer) His attitude toward me and his youngest daughter has changed. He takes it out on us. I explained to her that it is his illness. He has no energy. He is very depressed and down.

Depression was also a symptom that clinical teams were aware of. Indeed some were considering strategies to address this issue amongst their patients:

(Clinical Team, Heart Failure) Well, perhaps is there something proactive that we could do? Are we under-assessing our patients' moods? I know we treat them with our evidence- based medicine for their physical condition; maybe there is something else we could do to help psychologically?

PT 3 (Clinical team, Renal) I know she gets anxious and depressed at times. Social, support is difficult to obtain even when allocated, it does little to provide practical symptom relief or little to relieve the depression that seems to accompany this condition.

These extracts confirm that depression is a difficulty in these participants, but despite this recognition by their carers and their clinical team, few patients in this study were on anti-depressant therapy.

\section{Concerns about the future}

Many participants expressed concerns about the uncertainties regarding their health and how it might deteriorate in the future 
PT 1 (Renal) I would have anxieties and probably a lot of worries. I say to myself, "what will become of me?" I would be very concerned about having to go into a nursing home. That would be my biggest fear. I suppose I do worry about having to go into hospital.

Uncontrolled symptoms were also cited as causes of concern.

PT 4(Renal) My main worry for the future is this pain. If I could get rid of this pain, if they could do something about it, then I could worry about the future. As I see it now I have no future with this pain.

PT 8 (Carer, Heart Failure) If only they could get rid of his sickness. He hardly eats a thing and vomits a lot.

The carers also expressed concern at unresolved symptoms that caused patients significant distress.

PT 4 (Carer, Renal) I worry what is going to happen to him if he gets any worse? I worry about him being on his own more recently because his health has gone down. If they could get him something to help the pains.

Often participants freely spoke of their impending death and expressed worries for their families should they deteriorate quickly or die.

PT 13 (Respiratory) I know that I'm not going to get any better. I worry about my daughter if something happened to me.

Participants had often considered the final phase of their illness and discussed their wishes in relation to their death.

PT 11 (Heart Failure) My biggest worry is that I don't want to die in hospital. I want to die at home.

This extract is even more poignant in retrospect, because it was made by a patient with heart failure who died a few weeks later in the hospital's A\&E Department. 


\section{Discussion}

Findings from this study emphasise the high morbidity (Table 2), and variety of un-met needs experienced by this sample of patients. They illustrate the burden these place on both the patient and their carers, and shed light on the reasons why clinical teams find it difficult to adequately address the palliative care needs of these patients.

Palliative care in chronic illness has gained some prominence in the literature over the last decade, ${ }^{11,6}$ but from these findings it would seem that there remains a need for urgent progress. Patients and carers in this study described a variety of physical, emotional and social needs that were unanswered. The resources required to meet basic needs, such as a downstairs toilet or portable commode, were usually not of an expensive or scarce variety, and it would seem that holistic assessment of the patient could have readily identified these issues. The findings further illustrate that communication between primary and secondary care must be improved, to result in more joined-up services. It is recognized that although people dying with chronic illness tend to have frequent exacerbations which require hospitalization, the bulk of their care is provided at home and therefore hospital and community services should work together more effectively to ensure a better outcome for patients ${ }^{26,27}$.

However, perhaps the most illuminating finding was the expressed reluctance of some specialist clinicians to face the palliative care needs of their patients. Some clinical teams clearly stated that they found it difficult to discuss end of life issues with patients. It is evident from the data that these feelings emanated from sensitive and caring clinicians, who had known their patient for many years, yet found it difficult to spell out the lack of therapeutic options available in the final phase of their illness trajectory. We concur with other sources in the literature to suggest that this may be the necessary first step to making advances in the care of this population ${ }^{28,29}$. However, despite this we acknowledge that patients and carers in this study both appeared to understand the palliative nature of their treatment options. Given these findings, it is interesting, but not surprising that the palliative care team had been involved in only a minority of this sample's care. While we would not wish to infer that such specialist involvement is necessary in the case of every patient in the final stages of chronic illness, it would seem that aspects of this approach are a minimal requirement for this population ${ }^{18,26,19}$. 


\section{Conclusion}

The central message in this paper is that in order to address the needs of those in the final stage of chronic illness, clinical teams need to embrace the supportive and palliative care approach at an earlier stage and in a much more concerted fashion. The literature abounds with similar exhortations ${ }^{8,9,28}$. Many important lessons have been learned from cancer, and certainly there is the potential for these to be shared, but in addition, clinicians in chronic illness must develop their own specialist knowledge in this final chapter of the illness trajectory, just as they have at earlier stages. This challenge is an important and necessary step in knowledge generation, which should lead to higher quality care for individuals who have struggled for years with the wrath of chronic illness. There is no doubt that they deserve more co-ordinated and holistic care. The question remains, when and how, will we as clinicians extend our knowledge and skill base to rise to this challenge? 
Table 1: Disease specific inclusion criteria

\begin{tabular}{|l|l|l|}
\hline Renal Failure & Heart Failure & Respiratory Failure \\
\hline$\cdot$ GFR $\leq 10 \mathrm{mls}$ & $\cdot$ On optimal drug therapy & $\bullet$ On optimal drug therapy \\
\hline$\cdot$ Haemodialysis $\leq 2 \mathrm{yrs}$ & $\bullet$ Ejection Fraction $\leq 30 \%$ & $\bullet$ LTOT $+/$ - NIV \\
\hline$\cdot$ Dialysis 3 times per week & $\bullet$ NYHA Grade III-IV & $\bullet 2$ admissions in last year \\
\hline
\end{tabular}

Figure 1: Patient Characteristics

\begin{tabular}{|c|c|c|c|}
\hline Characteristic & $\begin{array}{l}\text { Renal Failure } \\
(n=6)\end{array}$ & $\begin{array}{l}\text { Respiratory Failure } \\
(\mathrm{n}=6)\end{array}$ & $\begin{array}{l}\text { Heart Failure } \\
(n=6)\end{array}$ \\
\hline $\begin{array}{l}\text { Age: } \\
<\quad 60 \\
61-75 \\
76-85 \\
>-86\end{array}$ & $\begin{array}{l}0 \\
4 \\
1 \\
0\end{array}$ & $\begin{array}{l}2 \\
3 \\
1 \\
0\end{array}$ & $\begin{array}{l}1 \\
3 \\
2 \\
0\end{array}$ \\
\hline Sex $M(F)$ & $3(3)$ & $3(3)$ & $4(2)$ \\
\hline $\begin{array}{l}\text { Marital Status: } \\
\text { Single } \\
\text { Married } \\
\text { Widowed/ Separated }\end{array}$ & $\begin{array}{l}0 \\
2 \\
3 \\
\end{array}$ & $\begin{array}{l}1 \\
3 \\
2 \\
\end{array}$ & $\begin{array}{l}0 \\
3 \\
3\end{array}$ \\
\hline $\begin{array}{l}\text { Months between } \\
\text { interview \& death } \\
\text { Median (Range) }\end{array}$ & $\begin{array}{l}(n=5 p t s) \\
12(1-32)\end{array}$ & $\begin{array}{l}(n=4 p t s) \\
20(2-28)\end{array}$ & $\begin{array}{l}(n=4 p t s) \\
14(4-26)\end{array}$ \\
\hline $\begin{array}{l}\text { Functional Status } \\
\text { Short Form } 36) \\
\text { (100 = best, } 0=\text { worst) } \\
\text { Physical Function } \\
\text { Role Physical } \\
\text { Role Emotional } \\
\text { Social Function } \\
\text { Mental Health } \\
\text { Vitality } \\
\text { Pain } \\
\text { General Health }\end{array}$ & $\begin{array}{l}16.6 \\
16.6 \\
16.6 \\
38.8 \\
60.6 \\
25.8 \\
33.3 \\
28.6 \\
\end{array}$ & $\begin{array}{l}30.0 \\
16.6 \\
33.3 \\
23.1 \\
40.8 \\
40.8 \\
40.8 \\
24.9 \\
\end{array}$ & $\begin{array}{l}20.0 \\
8.3 \\
27.7 \\
35.2 \\
56.0 \\
35.0 \\
51.8 \\
25.6 \\
\end{array}$ \\
\hline $\begin{array}{l}\text { HAD Scale } \\
\text { (10+= Clinically } \\
\text { significant) } \\
\text { Anxiety } \\
\text { Depression }\end{array}$ & $\begin{array}{l}7 \\
9\end{array}$ & $\begin{array}{l}10 \\
6 \\
\end{array}$ & $\begin{array}{l}8 \\
8\end{array}$ \\
\hline
\end{tabular}




\section{REFERENCES}

1. Office of National Statistics Annual Review of the registrar general on deaths in England and Wales. (2000) London; ONS

2. Boyd $K$ \& Sheikh A. Palliative care in chronic illness. British Medical Journal . 2005;330:

3. Murray SA, Boyd K, Sheikh A Palliative care in chronic illness. British Medical Journal. 2005; 330: 611-12.

4. Addington-Hall, J. M. and Higgginson, I. J. Palliative Care for Non-Cancer Patients. $\left(2^{\text {nd }}\right.$ ed) 2002: New York : Oxford University Press.

5. Hill, K.M. and Muers, M.F. Palliative care patients with non-malignant end stage respiratory disease. Thorax. 2000: 55, 979-981.

6. Coventry PA, Grande Ge, Richards DA \& Todd CJ Prediction of appropriate timing of palliative care for older adults with non-malignant life-threatening disease: a systematic review. Age and Aging 2005: 34 (3); 218 - 27.

7. Ellershaw, J. and Ward, C. Care of the Dying patient; the last hours or days of life. BMJ. 2003: 326, 30-34.

8. Lynn J Learning to care for people with chronic illness facing the end of life. Journal of the American Medical Association 2000: 284; 2508 - 11.

9. O'Brien, T., Welsh, J. and Dunn, F.G. ABC of palliative care, non-malignant conditions. BMJ. 1998: 316, 286-289.

10. Ward, W. The need for palliative care in the management of heart failure. Heart. 2002; 87: 294-298.

11.Addington-Hall, J. M. and McCarthy, M. Regional study of care for the dying: methods and sample characteristics. Palliative Medicine. 1995; 9: 27-35.

12. Gibbs, J. S. R., McCoy, A.S.M., Gibbs, L. M. E., Rogers, A. E. and Addington-Hall, J. M. Living with and dying from heart failure: the role of palliative care. Heart. 2002: 88 (Suppl II) 36-39.

13. Wallwork $L$ Palliative care in non-malignant conditions: a pragmatic response. International Journal of Palliative Nursing 2000: 6 (4); 186 - 8.

14. Gore, J. M., Brophy, C. J. and Greenstone, M, A. How well do we car for patients with end stage chronic obstructive pulmonary disease (COPD)? A comparison study of palliative care and quality of life in COPD and lung cancer. Thorax. 2000; 55: 1000-1006.

15. Drennan $\mathrm{J}$ and Cleary $\mathrm{J}$ Quality of life of patients on haemodialysis for end stage renal disease. Journal of Advanced Nursing 2005: 51 (6) 577 -586. 
16. Murtagh FEM, Murphy E, Shepherd KA, Donohoe P, \& Edmonds PM End of life care in end stage renal disease: renal and palliative care. British Journal of Nursing 2006:15; $1 ; 8-11$.

\section{Poppell}

18. Skilbeck JK \& Payne S End of life care: a discursive analysis of specialist palliative care nursing. Journal of Advanced Nursing 2005: 51 (4);325 - 34.

19. Luddington L, Cox S, Higginson I, Livesley B The need for palliative care for patients with non-cancer diseases: a review of the evidence. International Journal of palliative nursing. $2001: 7$ (5);221 - 6.

20. Parahoo, A K. Nursing Research Principles, Processes and Issues. 2006:Palgrave, Macmillan, London.

21. Walshe CE, Caress AL, Chew-Graham C, Todd CJ Case studies: a research strategy appropriate for palliative care. Palliative Medicine. 2004: 18 (8); 677 - 84.

22. Yin, R. K. Case Study Research: Design and Methods. 2002: (3 ${ }^{\text {rd }}$ ed) Vol 5, London; Sage Publications.

23. Ware, J.E. and Sherbourne, C.D. The MOS 36-item short form health survey (SF36), I: conceptual framework and item selection. Medical Care. 1992: 30, 473-483.

24. Zigmond, A.S. and Snaith, R.P. Hospital anxiety and depression scale. Acta Psychiatrica Scandinavia 1983: 67; 361-70.

25. Collaizzi, P. Psychological research as the phenomenologist views it. (1978) ........

26. Curtis JR, Engelberg RA, Wenrich MD, Au DH Communication about palliative care for patients with chronic obstructive pulmonary disease. Journal of Palliative Care 2005:21 (3):157 - 64 .

27. Stuart B Transition management: a new paradigm for home care of the chronically ill. Home health care management \& practice. 2003: 15 (2); 126 - 135.

28. Cox $P$ Managing chronic diseases: the palliative spectrum starts early on. British Medical Journal 2005: 330; 963.

29. Murray SA, Kendall M, Boyd K, Sheikh A Illness trajectories in palliative care. British Medical Journal 2005:330, 1007-1011.

Ware JE, Snow KK, Kosinski M, Gandek B. (1997) SF-36 Health Survey Manual \& Interpretation Guide. Boston: The Health Institute, New England Medical Center. 
McHorney CA, Ware JE, Lu JF, Sherbourne CD. (1994) The MOS 36 item short form health survey (SF-36): III. Tests of data quality, scaling assumptions, and reliability across diverse patient groups. Medical Care 32, 40-66.

Bjelland I, Dahl AA, Haug TT, Necklemann D. The validity of the Hospital Anxiety and Depression Scale - an updated literature review. J Psychosomatic Res 2002: 52: 69-77. 